\title{
Human Immunodeficiency Virus and Syphilis Among Blood Donors at Western Oromia, Ethiopia
}

\author{
Milkias Abebe $\mathbb{D}^{\prime}$ \\ Nagasa Marga ${ }^{2}$ \\ 'Department of Medical Laboratory \\ Sciences, Institute of Health Sciences, \\ Wollega University, Nekemte, Oromia, \\ Ethiopia; ${ }^{2}$ Department Medical \\ Laboratory, Bako Hospital, Bako, \\ Oromia, Ethiopia
}

Background: Blood transfusion saves lives and improves health, but many patients requiring transfusion do not have timely access to safe blood. Human immunodeficiency virus and syphilis are the commonest transfused transmitted infections and threats to blood recipients. Proper donor selection and screening of the donated blood for major transfusion-transmitted infections evidently reduced challenge in blood safety. Therefore, the objective of this study was to determine the sero-prevalence HIV and syphilis infections among blood donors at East Wollega, West Ethiopia.

Patients and Methods: A five-year (from January 2015 to December 2019) retrospective study was conducted by reviewing blood donor laboratory test results from Nekemte blood bank which is serving hospitals in Western Oromia. Blood donor data were analyzed by Statistical Package for Social Sciences version 20 software.

Results: The total of 17,810 individual's blood was screened during the study period. The overall prevalence of HIV, syphilis, and their co-infection was $222(1.25 \%), 142(0.80 \%)$, and $5(0.03 \%)$, respectively. The prevalence of HIV was associated with unmarried (AOR: 2.4; 95\% CI: 1.5, 5.2), male (AOR: 2.1; 95\% CI: 1.5, 2.9), and blood donors resident in a rural area (AOR: $1.5 ; 95 \% \mathrm{CI}: 1.5,5.9$ ). Besides, the prevalence of syphilis was associated with education, age, marital status and residence of study participant.

Conclusion: In the current study, the sero-prevalence of HIV and syphilis among blood donors was low, when it was compared to other sub-Saharan Africa country. However, to ensure the health of all recipients screening blood using standard methods is highly recommended.

Keywords: epidemiology, predictor, transfusion-transmitted infection, blood bank

\section{Introduction}

Blood transfusion is a life-saving therapeutic intervention in which globally more than 81 million units of blood are donated every year. Among these 18 million are not screened for an infection that is potentially capable of being transmitted by blood transfusion due to the blood is a vector for harmful transfusion transmissible infections. ${ }^{1}$ Human immunodeficiency virus and Treponema palladium are the common microorganisms for post-transfusion transmitted infection. ${ }^{2}$

The World Health Organization, to assure quality and safety, recommends screening of donated blood for a minimum of the major transfusion-transmitted infections (TTIs). Accordingly, screening for HIV, hepatitis B, hepatitis C, and syphilis should be mandatory. ${ }^{3,4}$ Annually, the worldwide infection rate of HIV

\footnotetext{
Correspondence: Milkias Abebe

Tel +251912863004

Fax +25I $57661-7980$

Email mickyelfe2I@gmail.com
} 
through blood transfusion alone ranges from 80,000 to $160,000 .^{5} \mathrm{Up}$ to 500 people acquire TTIs due to contaminated blood transfusion daily in Africa $^{5}$ and in subSaharan Africa, blood transfusion accounts for 5-10\% of HIV transmission. ${ }^{6}$ The estimated prevalence of HIV infection among blood donors in Ethiopia ranged from $0.1 \%-11.7 \%{ }^{7-9}$

There is a scarcity of comprehensive data on the prevalence and trends of major TTI among blood donors in the study area. Thus, the current study aimed to determine the prevalence and predictors of HIV and syphilis infections among blood donors in the Western Oromia, East Wollega, Ethiopia.

\section{Methods}

\section{Study Area}

The study was conducted in Nekemte Blood Bank, which is serving about 17 hospitals in Western Oromia. This blood bank is placed in the Nekemte town which is the capital city of the East Wollega Zone, Western Oromia, Ethiopia. Nekemte town is located $331 \mathrm{~km}$ west of the capital city, Addis Ababa.

\section{Study Design}

A five-year (January 2015 to December 2019) retrospective study was conducted by retrieving data from the Nekemte Blood Bank laboratory registration book.

\section{Study Population}

Blood donors who were registered on the laboratory registration of Nekemte Blood bank and screened for HIV and syphilis infection during the study period.

\section{Data Collection, Laboratory Examination, and Statistical Analysis}

The data extraction sheet was used to collect data regarding socio-demographic variables and blood donors laboratory test results of HIV and syphilis from Nekemte Blood Bank registration book. To identify HIV and syphilis of blood donors ELISA serological method was applied during the study period. In case of HIV, the WANTAI HIV 1 $+2 \mathrm{Ag} / \mathrm{Ab}$ ELISA test kit (Beijing Wantai Biological Pharmacy Enterprise Co., Ltd. China) was used. Besides, the blood donor sample was tested for anti-syphilis Ab: using DIALAB ELISA (Nora Kampitsch, MSc, India). Finally, the collected data were entered and analyzed by using a statistical package for the social science version 20 software.

\section{Results}

From a total of 17,810 blood donors, $70.1 \%(12,480)$ of the study participants were males. Of the total, a majority of $74.4 \%(13,245)$ blood donors were single, $59.4 \%$ $(10,572)$ were students, and $70 \%(12,456)$ donors were urban residents (Table 1 ).

The sero-prevalence of HIV was $1.25 \%(222 / 17,810)$. Of all study participants five $(0.03 \%)$ of them had coinfection of HIV and syphilis. Furthermore, of the total infected participants, the majority $(53.85 \%)$ of unmarried, $42.87 \%$ of males, $40.38 \%$ of age group within $18-30$, $34.89 \%$ of students, $47.53 \%$ of resident in urban, and $41.48 \%$ of participants had above the secondary level of education were infected by HIV (Table 1). Besides, the sero-prevalence of HIV was $0.06 \%(10 / 17,810)$ in 2015 and increased to $0.29 \%$ (52) in 2016 and $0.48 \%$ (86/ $17,810)$ in 2017 , then decreased to $0.26 \%(46 / 17,810)$ and $0.16 \%(28 / 17,810)$ in 2018 , and 2019 , respectively (Table 2).

The sero-prevalence of Syphilis was $0.8 \% \quad(142 /$ $17,810)$. Of all study participants five $(0.03 \%)$ of them had co-infection of HIV and syphilis. Moreover, of the total infected blood donors $29 \%$ of males, $34.89 \%$ of unmarried, $19.78 \%$ of age group within 35-65, $15.38 \%$ of students, and $24.45 \%$ resident in rural were infected with syphilis (Table 1). In addition, the seroprevalence of syphilis increased steadily from $0.06 \%(10 / 17,810)$ in 2015 to $0.02 \%(35 / 17,810)$ in 2019 (Table 2).

In the current study, the risk factors of HIV and syphillis were identified by multivariate logistic regression analysis. According to this study, the male blood donors were two times (AOR: 2.1; 95\% CI: 1.5-2.9) more likely to be infected by HIV compared to the counterpart. Besides, the unmarried study participant was also two times (AOR: 2.4; 95\% CI: 1.5-5.2) more likely to be infected by HIV when it was compared with that of married blood donor (Table 3).

Age, marital status, educational status, and residence were risk factors of syphilis in the present study. Those study participant at the age of $31-35$ years $(\mathrm{AOR}=2.8$; 95\% CI: $1.4,3.9)$ and 45-65 years $(\mathrm{AOR}=3.9 ; 95 \% \mathrm{CI}$ : 1.5-3.7), unmarried blood donors $(\mathrm{AOR}=2.5 ; 95 \% \mathrm{CI}$ : 1.4,3.2), donors with no formal education ( $\mathrm{AOR}=3.5$; 95\% CI: $1.9,4.5)$ and donor who were resident in rural 
Table I Socio-Demographics Characteristics, Prevalence of HIV and Syphilis Among Blood Donor, Western Oromia, Ethiopia from January 2015 to December 2019

\begin{tabular}{|c|c|c|c|}
\hline Variable & HIV Positive N (\%) & Syphilis Positive N (\%) & Total Infected Participants N (\%) \\
\hline \multicolumn{4}{|l|}{ Sex } \\
\hline Male & $156(42.85)$ & $107(29.40)$ & $263(72.25)$ \\
\hline Female & $66(18.13)$ & $35(9.62)$ & I0I (27.75) \\
\hline \multicolumn{4}{|l|}{ Age } \\
\hline $18-30$ & $147(40.38)$ & $27(7.42)$ & $174(47.80)$ \\
\hline $31-45$ & $52(14.29)$ & $43(11.8 I)$ & $95(26.10)$ \\
\hline $46-65$ & $23(6.32)$ & $72(19.78)$ & $95(26.10)$ \\
\hline \multicolumn{4}{|l|}{ Marital Status } \\
\hline Unmarried & $196(53.85)$ & $127(34.89)$ & $323(88.74)$ \\
\hline Married & $26(7.14)$ & $15(4.12)$ & $4 I(11.26)$ \\
\hline \multicolumn{4}{|l|}{ Occupational status } \\
\hline Student & 127 (34.89) & $56(15.38)$ & $183(50.27)$ \\
\hline Private worker & $22(6.04)$ & $15(4.12)$ & $37(10.16)$ \\
\hline Government Employs & $63(17.30)$ & $52(14.29)$ & 115 (31.59) \\
\hline Farmer & $10(2.75)$ & $19(5.22)$ & $29(7.97)$ \\
\hline \multicolumn{4}{|l|}{ Educational status } \\
\hline No formal & $47(12.91)$ & $61(16.76)$ & $108(29.67)$ \\
\hline Primary school & $24(6.59)$ & $9(2.47)$ & $33(9.06)$ \\
\hline Secondary and college & $|5|(4 \mid .48)$ & $72(19.78)$ & $223(61.26)$ \\
\hline \multicolumn{4}{|l|}{ Residence } \\
\hline Urban & $173(47.53)$ & $53(14.56)$ & $226(62.09)$ \\
\hline Rural & $49(13.46)$ & $89(24.45)$ & 138 (37.9|) \\
\hline
\end{tabular}

Abbreviations: N,number; \%, percent.

Table 2 Sero-Prevalence of HIV and Syphilis Infections with Respect to Donation Year Among Blood Donors, Western Oromia, Ethiopia from January 2015 to December 2019

\begin{tabular}{|l|l|l|l|}
\hline Year of Donation & No of Donor & HIV Positive N (\%) & Syphilis Positive N (\%) \\
\hline 2015 & 2693 & $10(0.06 \%)$ & $10(0.06 \%)$ \\
2016 & 2197 & $52(0.29 \%)$ & $30(0.16 \%)$ \\
2017 & 4178 & $86(0.48 \%)$ & $25(0.14 \%)$ \\
2018 & 4406 & $46(0.26 \%)$ & $42(0.24 \%)$ \\
2019 & 4336 & $28(0.16 \%)$ & $35(0.20 \%)$ \\
Total & 17,810 & $222(1.25 \%)$ & $142(0.80 \%)$ \\
\hline
\end{tabular}

Abbreviations: N,number; \%,percent.

$(\mathrm{AOR}=3.7 ; 95 \% \mathrm{CI}: 1.9,4.6)$ were more likely to be infected by syphilis compared their counterpart (Table 4).

\section{Discussion}

In the current study, the majority of the donors (70.1\%) were males, which were similar to the study in Gondar, ${ }^{7}$ and Nigeria. ${ }^{10}$ The numbers of female blood donors were few in the current study, and this may be attributed to behavioral and sociocultural drivers in Ethiopian society that the male is donated blood than female. ${ }^{11}$ Regarding trend, seroprevalence of HIV and syphilis with respect to year has shown a trend. However, a study from Gondar, Ethiopia has shown that consistent increment in the seroprevalence from 2010 to $2012 .{ }^{12}$ This might be a result of variation in the sero-prevalence of HIV and syphilis in the community since it is assumed that blood donors are a representative of the community. In addition, it might be as a result of the 
Table 3 Logistic Regression of HIV with Socio-Demographic Characteristics of Blood, Western Oromia, Ethiopia from January 2015 to December 2019

\begin{tabular}{|c|c|c|c|c|}
\hline \multirow[t]{2}{*}{ Variable } & \multicolumn{2}{|c|}{ HIV Status } & \multirow[t]{2}{*}{ COR $(95 \% \mathrm{Cl})$} & \multirow[t]{2}{*}{ AOR $(95 \% \mathrm{Cl})$} \\
\hline & Negative & Positive & & \\
\hline \multicolumn{5}{|l|}{ Sex } \\
\hline Female & 5264 & 36 & 1.00 & \\
\hline Male & 12,324 & 186 & $2.2(1.6-3.2)$ & $2.1(1.5-2.9)^{*}$ \\
\hline \multicolumn{5}{|l|}{ Age } \\
\hline $18-30$ & 11,313 & 147 & 1.00 & \\
\hline $31-45$ & 5840 & 52 & $0.7(0.4-2.9)$ & \\
\hline $46-65$ & 435 & 23 & $4.1(0.3-4.6)$ & \\
\hline \multicolumn{5}{|l|}{ Marital status } \\
\hline Married & 4539 & 26 & 1.00 & \\
\hline Unmarried & 13,049 & 196 & $2.6(1.6-5.5)$ & $2.4(1.5-5.2)^{*}$ \\
\hline \multicolumn{5}{|l|}{ Occupation } \\
\hline Student & 10,445 & 127 & 1.00 & \\
\hline Private worker & 1208 & 22 & $1.5(0.5-3.4)$ & \\
\hline Government Employs & 5413 & 63 & $0.9(0.3-1.8)$ & \\
\hline Farmer & 522 & 10 & I.5 $(0.8,2.4)$ & \\
\hline \multicolumn{5}{|l|}{ Educational Status } \\
\hline Primary school & 5419 & 24 & 1.00 & \\
\hline Secondary and college & 8367 & $15 \mid$ & $4.1(0.4-4.1)$ & \\
\hline No formal education & 3802 & 47 & $2.8(0.3-3.4)$ & \\
\hline \multicolumn{5}{|l|}{ Residence } \\
\hline Rural & 5305 & 49 & 1.00 & \\
\hline Urban & 12,283 & 173 & $1.5(1.6-6.6)$ & $1.5(1.5-5.9)^{*}$ \\
\hline
\end{tabular}

Note: *Statistically significance.

Abbreviations: $\mathrm{COR}$, crude odd ratio; $\mathrm{AOR}$, adjusted odd ratio; $\mathrm{Cl}$, confidence interval.

implementation of sensitive diagnostic test methods for screening of this infection.

The majority (64.5\%) study participants' age in the present study were ranging from 18 to 30 . Our result is similar to research conducted in North Gondar, ${ }^{12}$ Southwest Ethiopia, ${ }^{13}$ and Northwest Ethiopia. ${ }^{7}$ The highest number of donations in this age group (18-30 years) is due to the fact that active age groups (18-30) of the population are actively participating in blood donations. Besides, a good awareness was created on these age groups in the current study area.

The seroprevalence of HIV in the present study was $1.25 \%$. This result was similar to the study reported from Sudan, which was $1 \%{ }^{14}$ and $1.13 \%$ in South Africa. ${ }^{15}$ However, it was lower than a study conducted by different scholars in Ethiopia which was $4.5 \%$ of Diro et $\mathrm{al}^{16}$ and $3.8 \%$ of Tessema et $\mathrm{al}^{7}{ }^{7}$ and $3.8 \%$ in another country. ${ }^{17}$ The reason for the low prevalence of HIV seropositivity in the present study is due to the fact that there is good voluntary counseling test coverage in the study area. On the other hand, the prevalence of HIV among blood donors in the present study was higher than a similar study conducted in Jigjiga which was $0.1 \%,{ }^{9} 0.18 \%$ in Eretria $^{18}$ and $0.00 \%$ in Egypt in which there were no cases reported. ${ }^{19}$ The differences might be due to, differences in geographical locations, the burden of the disease in the society and difference in awareness of study participant on transmission and prevention of HIV.

In the current study, HIV infection was highest among blood donors who were male, college students, and 18-30 years of age which were similar to a report from another study area. ${ }^{20}$ Besides, in the present study sex, marital status, and residence of blood donors were risk factors for HIV seroprevalence. Male blood donors were more likely to be infected with HIV compared to female which was agreed with other research reported by different 
Table 4 Logistic Regression of Syphilis with Socio-Demographic Characteristics of Blood Donor, Western Oromia, Ethiopia from January 2015 to December 2020

\begin{tabular}{|c|c|c|c|c|}
\hline \multirow[t]{2}{*}{ Variable } & \multicolumn{2}{|c|}{ Syphilis Status } & \multirow[t]{2}{*}{ COR $(95 \% \mathrm{Cl})$} & \multirow[t]{2}{*}{ AOR $(95 \% \mathrm{Cl})$} \\
\hline & Negative & Positive & & \\
\hline \multicolumn{5}{|l|}{ Sex } \\
\hline Female & 5295 & 35 & 1.00 & \\
\hline Male & 12,373 & 107 & $1.3(0.8,2.9)$ & \\
\hline \multicolumn{5}{|l|}{ Age } \\
\hline $18-30$ & 7633 & 27 & 1.00 & \\
\hline $31-45$ & 5849 & 43 & $3.1(1.5,4.5)$ & $2.8(1.4-3.9)^{*}$ \\
\hline $46-65$ & 4186 & 72 & $4.8(1.8-4.7)$ & $3.9(1.5-3.7)^{*}$ \\
\hline \multicolumn{5}{|l|}{ Marital status } \\
\hline Married & 4550 & 15 & 1.00 & \\
\hline Unmarried & 13,118 & 127 & $3(1.7-3.6)$ & $2.5(1.4-3.2)^{*}$ \\
\hline \multicolumn{5}{|l|}{ Occupation } \\
\hline Student & 10,516 & 56 & 1.00 & \\
\hline Private worker & 1215 & 15 & $2.3(0.5-2.9)$ & \\
\hline Government Employs & 5424 & 52 & $1.8(0.1-4.5)$ & \\
\hline Farmer & 513 & 19 & $6.9(0.6-5.2)$ & \\
\hline \multicolumn{5}{|l|}{ Educational Status } \\
\hline Primary school & 5424 & 19 & 1.00 & \\
\hline Secondary and college & 8446 & 72 & $2.4(0.8,3.4)$ & \\
\hline No formal & 37,898 & 51 & $3.8(1.9-4.7)$ & $3.5(1.9-4.5)^{*}$ \\
\hline \multicolumn{5}{|l|}{ Residence } \\
\hline Urban & 12,403 & 53 & 1.00 & \\
\hline Rural & 5265 & 89 & $3.9(1.8-4.9)$ & $3.7(1.9-4.6)^{*}$ \\
\hline
\end{tabular}

Note: *Statistically significance.

Abbreviations: COR, crude odd ratio; AOR, adjusted odd ratio; $\mathrm{Cl}$, confidence interval.

scholars. ${ }^{7,21}$ This might be due to most females may know their HIV status at prenatal care which is mandatory for all pregnant women in our country. The present study has also shown that unmarried study participants were higher risk for HIV compared to married blood donors. The plausible explanation for this result is, married study participant might have stable sexual partners which decrease their risk of HIV infection. ${ }^{22}$ Moreover, rural blood donors were more likely to be infected with HIV than the urban donors. Similar result had been reported from another study area. ${ }^{23}$ The prevalence of HIV, which is high in rural study participant, is might be due to lack of awareness regarding the transmission and prevention of this virus from different electronic media.

The present study has shown that the prevalence of syphilis among study participant was $0.8 \%$, which was similar to the research done in Hawassa, Ethiopia. ${ }^{24}$ However, it was slightly higher than a similar study conducted in Eritrea $(0.49 \%)^{18}$ and lower than a study reported by scholars in Gondar which was $1.7 \%$, and Tanzania which was $4.7 \% .{ }^{17}$ These differences between different countries might be due to the quality of laboratory tests used to screen blood samples, the difference in prevention measures taken, the effectiveness of the program to choose blood donors. In this study, the prevalence of syphilis significantly associated with older blood donors within the age group 31-35 years and 45-65 years compared to the reference group. This result was similar with study conducted in different countries. ${ }^{1,11,17,25,26}$ However, our result was not inconsistent with some study conducted in our country like in Gondar and Jigjiga. ${ }^{9}$ Similar to study conducted in Eastern Ethiopia, ${ }^{27}$ in the current study unmarried blood donors, donors with no formal education and donors who were living in rural were highly vulnerable to syphilis compared to their counterparts. 
The current study has provided a good data on the prevalence and some associated predictors of HIV and syphilis due to the study tried to use long year blood donor's history with large sample size. However, some variables were missed since the study was retrospective, which was reviewed from laboratory registration book of the blood bank.

\section{Conclusion}

The result of the current study has shown that the seroprevalence of HIV and syphilis was low compared to study from countries in sub-Saharan Africa. Though, a substantial percentage of study participants had HIV and syphilis infections. Therefore, strict selection of blood donors using standard methods is necessary to make sure the health of the recipients is protected. Besides, increasing the awareness of rural people regarding the transmission and prevention of infection required to minimize the burden of HIV and syphilis should be encouraged.

\section{Abbreviations}

ELISA, enzyme linked immunosorbent assay; HIV, human immunodeficiency virus; SPSS, Statistical Package for Social Sciences; TTIs, transfused transmitted infections; WHO, World Health Organization.

\section{Data Sharing Statement}

All data generated or analyzed during this study were included in this article.

\section{Ethics Approval and Consent to Participate}

This research was conducted after obtaining ethical clearance from an ethical review committee of the Institute of Health Science, Wollega University with reference number DMLS/127/11. All data and samples obtained from them were kept confidential by using codes instead of any personal identifiers and were meant only for the purpose of the study. Besides, the study was conducted in accordance with the Declaration of Helsinki.

\section{Acknowledgments}

We would like to express our special thanks to all staff of the Nekemte blood bank for their support during data collection.

\section{Author Contributions}

All authors made a significant contribution to the work reported, whether that is in the conception, study design, execution, acquisition of data, analysis and interpretation, or in all these areas; took part in drafting, revising or critically reviewing the article; gave final approval of the version to be published; have agreed on the journal to which the article has been submitted; and agree to be accountable for all aspects of the work.

\section{Disclosure}

The authors declare that they have no competing interests in this work.

\section{References}

1. Adu-poku F, Agboli E, Tarkang EE, Region HV, Region HV. Seroprevalence of transfusion-transmissible infections among blood donors in the Hohoe Municipal Hospital, Ghana: 2015-2016: a retrospective hospital-based cross-sectional study. PAMJ Clin Med. 2020;2:12.

2. Song Y, Bian Y, Petzold M, Ung COL. Prevalence and trend of major transfusion-transmissible infections among blood donors in Western China, 2005 through 2010. PLoS One. 2014;9(4):e94528. doi:10.1371/journal.pone.0094528

3. Deshpande RH, Bhosale S, Gadgil PA, Sonawane M. Blood donor's status of HIV, HBV, HCV and syphilis in this region of Marathwada, India. J Krishna Inst Med Sci Univ. 2012;1(2):111-116.

4. Negash M, Ayalew M, Geremew D, Workineh M. Seroprevalence and associated risk factors for HIV, hepatitis B and C among blood donors in South Gondar District blood Bank, Northwest Ethiopia. BMC Infect Dis. 2019;19:430. doi:10.1186/s12879-0194051-y

5. World Health Organization. 2020. Available from: https://www.who. int/news-room/fact-sheets/detail/blood-safety-and-availability. Accessed July 17, 2021.

6. World Health Organization. Blood safety and availability fact sheet. 2019. Available from: https://www.who.int/news-room/fact-sheets/ detail/blood-safety-and-availability. Accessed July 17, 2021.

7. Tessema B, Yismaw G, Kassu A, et al. Seroprevalence of HIV, HBV, $\mathrm{HCV}$ and syphilis infections among blood donors at Gondar University Teaching Hospital, Northwest Ethiopia: declining trends over a period of five years. BMC Infect Dis. 2010;10:111. doi:10.1186/1471-2334-10-111

8. Bisetegen FS, Bekele FB, Ageru TA, Wada FW. Transfusiontransmissible infections among voluntary blood donors at Wolaita Sodo University Teaching Referral Hospital, South Ethiopia. Can J Infect Dis Med Microbiol. 2016;2016:6. doi:10.1155/2016/8254343

9. Mohammed Y, Bekele A. Seroprevalence of transfusion transmitted infection among blood donors at Jijiga blood bank, Eastern Ethiopia: retrospective 4 years study infectious diseases. BMC Res Notes. 2016;9:129. doi:10.1186/s13104-016-1925-6

10. Nwankwo E, Momodu I, Umar I, Musca B, Adeleke S. Seroprevalence of major blood-borne infections among blood donors in Kano, Nigeria. Turk J Med Sci. 2012;42(2):337-341.

11. Siraj N, Achila OO, Issac J, et al. Seroprevalence of transfusiontransmissible infections among blood donors at National Blood Transfusion Service, Eritrea: a seven- year retrospective study. BMC Infect Dis. 2018;18:264. doi:10.1186/s12879-018-3174-x 
12. Biadgo B, Shiferaw E, Woldu B, Alene KA, Melku M. Transfusiontransmissible viral infections among blood donors at the North Gondar district blood bank, northwest Ethiopia: a three year retrospective study. PLoS One. 2017;12(7):e0180416. doi:10.1371/journal.pone.0180416

13. Kebede W, Mekonnen Z, Gerbi A, Abebe G. Transfusion-transmissible infection surveillance among blood donors in Southwest Ethiopia: a six years retrospective study. Asian Pac J Trop Dis. 2017;7(3):156-161. doi:10.12980/apjtd.7.2017D6-384

14. Abou MA, Abdalla M, Eltahir YM, Ali AS. Seroprevalence of hepatitis $\mathrm{B}$ virus and hepatitis $\mathrm{C}$ virus among blood donors in Nyala, South Dar Fur, Sudan. Virol J. 2009;6:1-4. doi:10.1186/ 1743-422X-6-146

15. Vermeulen M, Swanevelder R, Chowdhury D, et al. Use of blood donor screening to monitor prevalence of HIV and hepatitis B and C viruses, South Africa. Emerg Infect Dis. 2017;23(9):1560-1563. doi:10.3201/eid2309.161594

16. Diro E, Alemu S, G/yohannes A. Blood safety \& prevalence of transfusion transmissible viral infections among donors at the Red Cross Blood Bank in Gondar University hospital. Ethiop Med J. 2008;46(1):7-13.

17. Matee MIN, Magesa PM, Lyamuya EF. Seroprevalence of human immunodeficiency virus, hepatitis $\mathrm{B}$ and $\mathrm{C}$ viruses and syphilis infections among blood donors at the Muhimbili National Hospital in Dar Es Salaam, Tanzania. BMC Public Health. 2006;6:21. doi:10.1186/1471-2458-6-21

18. Fessehaye N, Naik D, Fessehaye T. Transfusion transmitted infections a retrospective analysis from the National Blood Transfusion Service in Eritrea. Pan Afr Med J. 2011;9:40. doi:10.4314/pamj.v9i1.71219

19. Nada HA, Atwa M. Seroprevalence of HBV, HCV, HIV and syphilis markers among blood donors at Suez Canal University Hospital Blood Bank. J Blood Disord Transf. 2013;5(1):177.

20. Yang S, Jiao D, Liu C, et al. Seroprevalence of human immunodeficiency virus, hepatitis $\mathrm{B}$ and $\mathrm{C}$ viruses, and Treponema pallidum infections among blood donors at Shiyan, Central China. BMC Infect Dis. 2016;16(1):531. doi:10.1186/s12879-016-1845-Z
21. Jary A, Dienta S, Leducq V, et al. Seroprevalence and risk factors for HIV, HCV, HBV and syphilis among blood donors in Mali. BMC Infect Dis. 2019;19:1064. doi:10.1186/s12879-019-4699-3

22. Kposowa AJ. Marital status and HIV/AIDS mortality: evidence from the US National Longitudinal Mortality Study. Int J Infect Dis. 2013;17(10):e868-e874. doi:10.1016/j.ijid.2013.02.018

23. Yambasu EE, Reid A, Owiti P, Manzi M, Murray M, Edwin A. Hidden dangers-prevalence of blood borne pathogens, hepatitis B, C, HIV and syphilis, among blood donors in Sierra Leone in 2016: opportunities for improvement: a retrospective, cross-sectional study. Pan Afr Med J. 2018;30:44. doi:10.11604/pamj.2018.3 0.44 .14663

24. Bonja F, Hussein M, Alemu J, Gemechu D, Birhaneselassie M. The prevalence of transfusion transmitted infections: a focus on hepatitis B virus among blood donors at Hawassa blood bank center, Southern Ethiopia. Int $J$ Blood Transfus Immunohematol. 2017;7:7-14. doi:10.5348/ijbti-2017-29-OA-2

25. Bekele T, Adera A, Degu G, et al. Seroprevalence and diagnosis of HIV, HBV, HCV and syphilis infections among blood donors. Hum Antibodies. 2017;25(1):39-55.

26. Teklemariam Z, Mitiku H, Weldegebreal F. Seroprevalence of transfusion transmissible viral infections (HIV, HBV and HCV) among voluntary blood donors at University of Gondar Comprehensive Specialized Hospital, Gondar; Northwest Ethiopia. BMC Hematol. 2018;18:24. doi:10.1186/s12878-018-0115-2

27. Heyredin I, Mengistie B, Weldegebreal F. Sero-prevalence of transfusion-transmittable infections and associated factors among blood donors in Eastern Ethiopia: an Institutional-based cross-sectional study. SAGE Open Med. 2019;7:2050312119834468. doi:10.1177/ 2050312119834468
Journal of Blood Medicine

\section{Publish your work in this journal}

The Journal of Blood Medicine is an international, peer-reviewed, open access, online journal publishing laboratory, experimental and clinical aspects of all aspect pertaining to blood based medicine including but not limited to: Transfusion Medicine; Blood collection, Donor issues, Transmittable diseases, and Blood banking logistics; Immunohematology; Artificial and alternative blood based therapeutics; Hematology; Biotechnology/nanotechnology of blood related medicine; Legal aspects of blood medicine; Historical perspectives. The manuscript management system is completely online and includes a very quick and fair peer-review system. Visit http://www.dovepress.com/testimonials.php to read real quotes from published authors. 